\title{
A thermodynamic model of the sympathetic and parasympathetic nervous systems
}

\author{
Giorgio Recordati* \\ Centro Fisiologia Clinica ed Ipertensione, Universita' di Milano ed Ospedale Maggiore, IRCCS, Via F. Sforza 35, 20122 Milan, Italy
}

Received 12 July 2002; received in revised form 9 October 2002; accepted 10 October 2002

\begin{abstract}
In light of the nonequilibrium thermodynamics by I. Prigogine, the autonomic nervous system as a whole may be viewed as a dissipative structure progressively assembled in the course of evolution, plastically and rhythmically interfaced between forebrain, internal and external environments, to regulate energy, matter and information exchanges. In the present paper, this hypothesis is further pursued to verify whether the two main divisions of the autonomic nervous system, the sympathetic and parasympathetic systems, may support different types of exchange with the external environment. Previous data from hypothalamic stimulation experiments, studies of locus coeruleus function and available data on behavioral functional organization indicate that (1) tight engagement with the external environment, (2) high level of energy mobilization and utilization and (3) information mainly related to exteroceptive sensory stimulation characterize a behavioral prevalence of sympathoadrenal activation. On the other hand, (1) disengagement from the external environment, (2) low levels of internal energy and (3) dominance of proprioceptive information characterize a behavioral prevalence of vagal tone. Behavioral matter exchanges such as feeding, drinking, micturition and defecation are equally absent at the extreme of sympathoadrenal and vagally driven behaviors. The autonomic nervous system as a whole is genetically determined, but the sympathoadrenal system has been mainly designed to organize the visceral apparatus for an action to be performed by the biological system in the external environment and to deal with the novelty of task and of the environment, while the functional role of the parasympathetic is to prepare the visceral apparatus for an action to be performed by the biological system on itself, for recovery and self-protection (homeostasis), and is reinforced by repetition of phylo- and ontogenetically determined patterns. The available clinical data further support this interpretation indicating that an increased sympathetic and a decreased vagal tone may represent a consistent risk factor for cardiovascular diseases.
\end{abstract}

(C) 2002 Elsevier Science B.V. All rights reserved.

Keywords: Autonomic nervous system; Dissipative structure; Muscle exercise; Mental arousal; Emotions; Hibernation; Sleep; Hypometabolism; Grooming; Diving; Deep breathing; Post-exercise post-stress recovery

\section{Introduction}

The peripheral activity of the sympathetic and parasympathetic nervous systems, the two main divisions of the autonomic nervous system, is hierarchically coordinated by neuronal networks in the forebrain, hypothalamus, midbrain and medulla (Dampney, 1994; Benarroch, 1999; Jänig and McLachlan, 1999; Spyer, 1999; Morrison, 2001). Different behaviors and visceral reflexes activate the peripheral branches of the autonomic nervous system along characteristic patterns, which in many cases have been carefully

\footnotetext{
* Tel.: +39-2-5503-3528; fax: +39-2-503-20480.

E-mail address: Giorgio.Recordati@unimi.it (G. Recordati).
}

mapped (Furness et al., 1999; Spyer, 1999; Folkow, 2000; Szekely, 2000; Morrison, 2001).

Starting from the definition of the biological system as a thermodynamic open system continuously exchanging matter, energy and information with its environments (von Bertalannfy, 1950; Prigogine, 1978; Omodeo, 1983), and from the thermodynamic approach to the biological system by Nicolis and Prigogine (1977) and Prigogine (1978), it has been recently proposed (Recordati, 2002) that the autonomic nervous system as a whole may be considered a complex structure which originated and became organized in the course of evolution by the progressive assembly of discrete neuronal dissipative structures. The main functional role of the autonomic system as a whole is that of inducing, maintaining and regulating ordered exchanges of matter, energy and information within and among its 
environments, which are the forebrain, the fluid matrix or internal environment and the external environment. Because of its inherited plastic and rhythmic properties, stimuli arising from these environments may in turn contribute to the structural and functional organization of the autonomic nervous system. Then, the autonomic nervous system as a whole may be described as a dissipative structure plastically interfaced between the forebrain, body and external environment to regulate and maintain ordered exchanges of matter, energy and information in a continuous interplay between function, structure and fluctuations (Prigogine, 1973, 1975, 1978; Jänig, 1988; Jänig and Häbler, 1999; Recordati, 2002).

A system is thermodynamically defined as open on the bases of matter, energy and information exchanges with the environment. In this context, the term information is not only related to the sensory input and functional properties of neurons but it is also a measure of the internal order of the system and of the so-called "negative entropy" (von Bertalannfy, 1969; Prigogine, 1996). Since matter, energy and information exchanges include all possible stimuli acting on the system and all possible actions induced by it, they are the key elements to attempt a thermodynamic qualification not only of the autonomic nervous system as a whole but also of sympathetic and parasympathetic functions. Previous data indicate that such an endeavour is possible.

By electrically stimulating hypothalamic areas, Hess (1957) described a dynamogenic zone peripherally connected to the sympathetic nervous system, directed to mobilize and utilize energies called the ergotropic system, and an adynamogenic zone, peripherally connected to the parasympathetic, promoting restorative processes called the trophotropic-endophylactic system. More recently, Aston-Jones et al. (1984, 1994), Elam et al. (1986), Van Bockstaele and Aston-Jones (1995) and Usher et al. (1999) have described that the locus coeruleus neurons that contribute to the general arousal level of the animal are markedly activated whenever the animal, interrupting an internally oriented behavior such as sleep, grooming and food consumption, initiates a behavior directed to the external environment and driven by prevalent exteroceptive sensory information such as alertness and increased level of vigilance. These same concepts have been utilized by Henry $(1994,1997)$ to attempt an understanding of the neurohumoral regulation of post-traumatic stress disorders. In addition, a phylogenetic staging of the autonomic nervous system development, through the different behaviors of immobilization, fight and flight and recovery, has been fostered to support interpretation of social behavior and stress vulnerability (Porges, 1995, 2001). Hence, both the utilization of metabolic energies in relation to the type of work to be done and the direction of the work with respect to the external environment have become relevant factors to behaviorally characterize sympathetic and parasympathetic functions. By combining these previous observations with the thermodynamic model just described, the first step towards the description of matter, energy and information exchanges qualifying sympathetic and parasympathetic actions will be made in the present paper. This attempt will be based on the analysis of behaviors characterized by a clear dominance of sympathetic and parasympathetic on cardiovascular functions, leaving apart, for the moment, those behaviors which display a simultaneous and similar activation of both systems, such as sexual activity, and those mainly directed to the exchanges of materials with the external environments such as feeding, drinking, micturition and defecation.

Throughout this presentation, sensory information is described according to Sherrington's classification of exteroceptive and proprioceptive sensory information with the extension proposed by Moruzzi (1979) that telereceptor information may be included in the exteroceptive term while the information coming from enteroreceptors and from all visceral organs may be included in the proprioceptive category. Along this classification, reflexes may be divided into two main groups: those elicited by stimuli arising from the outside environment and those arising from inside the biological system (Moruzzi, 1979, p. 180).

From these given premises, the following is divided into three main sections: the first for the description of behaviors with prevalent sympathetic activation, the second for behaviors with parasympathetic dominance and the third for the physiological and pathophysiological implications arising from the proposed approach.

\section{Behavioral conditions characterized by a prevalence of sympathetic tone}

\subsection{Behaviors}

The first sympathetic activation occurs at birth, during delivery, the transition from fetal to newborn life, and it is elicited by a sensory input from cutaneous cold-sensitive thermoreceptors and mediated by the activation of supramedullary structures (Segar et al., 1994; Mazursky et al., 1996; Segar, 1997).

Exit from hibernation is also characterized by an increase in sympathetic activity that promotes the increase in heart rate and rate of breathing and precedes any appearance of vagal tone. The drive for this sympathetic activation is still unknown (Milsom et al., 2001).

Similarly, every morning, the transition from sleep to wakefulness, the moment of eye opening to the stimulatory effects of light is characterized by a prompt increase in sympathetic activity, blood pressure and heart rate (Conway et al., 1983, 1984; Furlan et al., 1990).

Muscle exercise and mental arousal are the behaviors more often utilized to characterize the activation of the sympathetic nervous system during wakefulness. 


\subsubsection{Muscle exercise}

From the low levels of muscle work required by standing and light isometric (hand grip) and isotonic exercise to the extremes of strenuous muscle exercise and the fight and flight reaction, there is a continuum of ordered activation of the sympatho-adrenal system in relation to the amount of work to be performed in the external environment, oxygen consumption and the level of engagement of the biological system with the environment (Rowell, 1993; DiCarlo and Bishop, 1999). From resting heart rate values to a rate of about $100 \mathrm{bpm}$, vagal withdrawal provides the initial rapid changes in heart rate and cardiac output while sympathetic activation becomes the dominant factor in controlling further heart rate increments (Rowell, 1993, p. 172). Cardiac vagal tone and baroreceptor reflexes are unloaded by the central command and excitation of group III mechanoreceptors and group IV metaboreceptors muscle afferents (Coote et al., 1971; Victor et al., 1989; DiCarlo and Bishop, 1999; Coote and Bothams, 2001). The activation of the sympathetic has been very well documented by recordings of muscle sympathetic nerve activity, the increment of which is proportional to the muscle mass and the severity of exercise (Mark et al., 1985; Rowell, 1993, p. 410; Seals, 1993), by studies of sympathovagal balance and spectral analysis of blood pressure and heart rate variabilities (Pagani et al., 1988; Piazza et al., 1995; Iellamo et al., 1999), by determination of plasma catecholamines and renin-angiotensin system changes (Rowell, 1993, p. 234) and by the effects of surgical sympathectomy and $\beta$-blockade (Opie, 1985; Shepherd, 1985). All these changes are ordered and may be optimized and controlled by training.

\subsubsection{Mental arousal}

Activation of the sympathetic nervous system by an increase in central arousal level characterizes the responses to mental stress in all its different quantification methods as a reflex of the engagement of the biological system with stressful environmental conditions. Emotional expression, in general, is also accompanied by an activation of the sympathetic activity to the cardiovascular system (Zanchetti et al., 1972; Le Doux, 1987). Similarly, heart rate, blood pressure and renal sympathetic nerve activity changes have been documented for humans and experimental animals subjected to environmental stressful stimuli involving the stimulation of telereceptors such as loud noise, bright light, air jet on the face and cold pressor test (Burke et al., 1998).

Worth of interest is that both muscle exercise and emotional arousal are characterized by cutaneous vasoconstriction. This may indicate that together, with a prompt mobilization and utilization of energies, heat should be simultaneously and adequately conserved. In the course of muscle exercise, the initial cutaneous vasoconstriction is reversed to vasodilation to meet the thermoregulatory needs of the biological system, but for any given internal temperature, skin blood flow is lower during exercise than at rest (Rowell, 1993, p. 224; DiCarlo and Bishop, 1999).
In addition to integrating influences from higher brain centers (mental arousal and central command) and from the internal environment (for example, temperature regulation and distribution of cardiac output), the sympathetic output to target organs is also dependent on external environmental forces such as the acceleration of gravity. The experimental observation in humans undergoing increments in gravity acceleration, the muscle sympathetic nerve activity increases to counteract blood volume displacement, while in microgravity, it is completely inhibited, supports this view (Iwase et al., 1998).

The emotional quality of novelty also deserves to be mentioned in relation to sympathetic nervous system activation.

\subsubsection{Novelty of task and of the environment}

As already presented at the beginning of this section, novelty, such as exit from fetal life, hibernation and sleep, is by itself a stimulus for sympathetic activation. It is well known that both positive and negative (aversive) emotions may entrain sympathetic activation. With the exception of emotional arousal from creative thoughts and feelings, emotions are usually elicited by exteroceptive stimulation, by new tasks to be performed and by new environments. Cardiovascular reactivity peaks early during the initial presentation of a demanding task, when novelty and uncertainty are greatest (Kelsey et al., 1999, 2000). The wellknown helpful effect of nonselective beta-blockade in sustaining public performance is a valid example extendable to emotional arousal in general (Clarkson and Thompson, 1997; Tyrer, 1988).

The cardiovascular changes which occur during muscle exercise and mental arousal are a useful example of the autonomic nervous system as an interface positioned among forebrain structures, internal and external environments, to induce adequate alterations of the visceral apparatus, allowing the biological system to perform work in the environment. As already pointed out, this work, in its most general terms, concerns the ordered exchanges of matter, energy and information which will be considered next.

\subsection{Matter}

During muscle exercise and emotional stimuli, owing to the inhibitory effects on gastrointestinal and bladder smooth muscles and to a diffuse visceral vasoconstriction produced by sympathetic stimulation (Zanchetti, 1986; Folkow, 2000), exchanges of matter with the environment such as feeding, drinking and evacuations of waste products are usually halted.

\subsection{Energy}

In awake unanaesthetized animals and in awake relaxed humans, the level of postganglionic sympathetic nerve activity directed to the target organs is generally low 
Table 1

Matter, energy and information exchanges characterizing sympathetic and parasympathetic behavioral dominance

\begin{tabular}{|c|c|c|c|c|c|}
\hline & Behaviors & Matter exchanges & Energy & Information & $\begin{array}{l}\text { Recovery of } \\
\text { function }\end{array}$ \\
\hline SNS & $\begin{array}{l}\text { active engagement with the } \\
\text { external environment }\end{array}$ & none & $\begin{array}{l}\text { increased mobilization } \\
\text { and utilization }\end{array}$ & mainly exteroceptive & unknown \\
\hline PNS & $\begin{array}{l}\text { disengagement from external } \\
\text { environment for rest and recovery }\end{array}$ & $\begin{array}{l}\text { none for the } \\
\text { cardiovascular } \\
\text { system }\end{array}$ & $\begin{array}{l}\text { decreased, favoring } \\
\text { hypometabolism }\end{array}$ & mainly proprioceptive & yes \\
\hline
\end{tabular}

SNS: sympathetic nervous system.

PNS: parasympathetic nervous system.

(McAllen and Malpas, 1997; Macefield et al., 2002). Nonetheless, it has been recently demonstrated that a small percentage of the total resting metabolic rate in healthy adult humans is tonically supported by a $\beta$-adrenergic sympathetic effect (Bell et al., 2001; Monroe et al., 2001). Above this resting level, the sympathetic provides the input for facultative thermogenesis that quantifies the cellular reactions in excess of those required to maintain the organism above its basal state, such as thermogenesis associated with muscular activities, response to cold and food intake (Landsberg and Young, 1978; Landsberg et al., 1984). In addition to increasing the rate of cellular metabolism, the sympathetic increases mobilization and utilization of metabolic energies, owing to its well-known glycogenolytic, lipolytic and gluconeogenetic effects (Reaven et al., 1996; Mcdonald, 1999; Szekely, 2000). In addition, well documented are the responses to environmental cooling and to hypoglycemia (Morrison, 2001), as well as the metabolic effects of epinephrine and the indirect sympathomimetic effect of amphetamines (Hoffman, 2001).

\subsection{Information}

The behavioral conditions referred to by Hess and AstonJones are all characterized by the fact that the subject attention is mainly driven by exteroceptive information. With respect to the defence reaction, it must be noted that it preserves the integrity of the individual because it is directed towards elimination or avoidance of threatening external causes (Mancia et al., 1974; Zanchetti, 1986). In defence reaction, the drive from exteroceptive stimuli is so strong, however, that proprioceptive perception is usually impaired, as reflected by the unperceived injuries sustained during sport or in battlefield, and the hypoalgesic effect of stressful conditions (Zieglgänsberger, 1986, pp. 582 and 612). These conditions are also accompanied by a consistent increase in blood pressure, which is characterized by a decrease in baroreceptor sensitivity and by a simultaneous shift of the set-point to higher pressures (Rowell, 1993, p. 469; DiCarlo and Bishop, 1999). Hence, in addition to a raised threshold for proprioceptive information at the extreme of the sympathetically driven conditions, the biological system looses, at least for what blood pressure is concerned, the so-called homeostatic regulation of the internal environment. Training increases the sensitivity of the baroreceptor reflex, making the emotional component of strenuous muscle exercise more easily controllable and facilitating proprioception from muscle and joints.

\subsection{Summary}

The activation of the sympathetic nervous system, either elicited by a central voluntary command (muscle work) or by an involuntary central arousal (emotion and stress) or by reflexes (increase in gravity vector, decrease in temperature and hypoxia), is thus directed to increasing energy mobilization and utilization, to increasing and redistributing internal gradients functionally organized along evolutionary pattern and to preparing the visceral apparatus for an action to be performed by the $\mathrm{BS}$ in the external environment. The behavioral conditions directed to performing work in the external environment and characterized by a predominant sympathetic tone share the following common properties: (1) high level of energy mobilization and utilization, (2) prevalent conscious exteroceptive information, mainly driven by the novelty of task and of the environment and (3) absence of matter exchanges with the external environment (Table 1).

\section{Behavioral conditions characterized by a prevalence of vagal tone}

\subsection{Behaviors}

\subsubsection{Hibernation}

Parasympathetic activation mediates the autonomic events occurring during entrance in hibernation, a long lasting disengagement from the external environment, characterized by decreases in heart rate, breathing frequency and metabolic rate (Milsom et al., 2001). During deep hibernation, when body temperature may stabilize around $4{ }^{\circ} \mathrm{C}$, the sympathetic and parasympathetic tones are both greatly reduced or absent, thus confirming the well-known association between fasting, hypometabolism, hypothermia and reduced sympathetic activity (Milsom et al., 2001; Szekely, 2000). While both cortical inhibition and activation of hypothalamic centers seem to accompany the increased 
vagal drive during entrance in hibernation, the exact sequence of events and the physiological mechanisms which lead to the hypometabolic state of hibernation are still unknown (Kilduff et al., 1993; Milsom et al., 2001).

\subsubsection{Sleep}

Sleep is a recovery process during which the biological system decreases its sensory alertness, the level of reticular activation is reduced, and the individual separates and disengages from the external environment (Moruzzi, 1969; Hobson and Steriade, 1986; Ancoli-Israel, 2001). This complex behavioral condition is characterized by a marked decline in sympathetic activity to the peripheral organs, with the muscle sympathetic nerve activity reaching a minimum level during nonrapid-eye-movement sleep stages 3 and 4 (Somers et al., 1993; Malliani, 2000; Lugaresi et al., 2001). Spectral analysis of blood pressure and heart rate variability has shown that the decline in sympathetic activity is accompanied by an increase in vagal tone (Furlan et al., 1990; Scholz et al., 1997; Malliani, 2000, pp. 85-87). These changes in sympatho-vagal balance are accompanied by the well-known circadian decline in blood pressure and heart rate and by an increase in the baroreceptor-reflex gain (Smyth et al., 1969; Conway et al., 1983).

The bursts of sympathetic activation and the simultaneous increases in heart rate, blood pressure and rate of breathing occurring during rapid-eye-movement sleep are the outcome of endogenous brain reactivation which occurs in an open-loop condition with respect to the external environment (Parmeggiani, 1985; Lugaresi et al., 2001). During rapid-eye-movement sleep, for example, the hypothalamic preoptic thermoregulatory structures are inactivated and the homeostatic temperature regulation is lost: shivering thermogenesis, thermal tachypnea, thermoregulatory vasomotion and sweating are suppressed or depressed during desynchronized sleep (Parmeggiani, 1985).

Sleep may be described, therefore, as a behavioral condition characterized by the disengagement of the biological system from the external environment for recovery and selfprotection, by a low level of energy mobilization and utilization, lower production of internal gradients and predominance of vagal tone. Similar characteristics are also common to all other behaviors characterized by a prevalence of the parasympathetic nervous system tone during wakefulness.

\subsubsection{Vita parva}

Hypometabolism and hypothermia are the consequences of both acute fasting or chronic starvation and characterize a life style maintained on a low scale ("vita parva") (Szekely, 2000). Both in humans and experimental animals, it has been demonstrated that the decrease in energy intake and the consequent decrease in body weight are associated with a decrease in sympathetic activity (Landsberg and Young, 1978; Sakaguchi et al., 1988; Schwartz and Seeley, 1997; Szekely, 2000) and an increase in parasympathetic tone to the heart and circulation (Hirsch et al., 1991; Aronne et al., 1995; Overton et al., 2001; Rissanen et al., 2001). At the extreme of this tendency is anorexia nervosa, which is characterized by a marked increase in parasympathetic tone to the heart (Petretta et al., 1997).

Fasting hypometabolism is a metabolic depression which is mainly dependent on efferent sympathetic depression and a reduced amount of thyroid hormones, rather than on a direct vagal efferent effect, although vagal tone to the heart and circulation is increased (Szekely, 2000).

\subsubsection{Grooming}

Grooming describes a behavior concerned with the primary biological function of caring of the body surface. Similar behaviors are "scratching", "preening", "rubbing against objects" and "dust, sand, mud and sun bathing" (Spruijt et al., 1992) and by spreading saliva on the fur in a hot environment (Nagashima et al., 2000). These behaviors may be directed at the body of the subject (autogrooming) and also at that of conspecifics (social grooming) (Spruijt et al., 1992). Allo- and social grooming find their origin in the interiorization and repetition of the infant-mother relationship. Because grooming mainly occurs after various activities and stressors, it seems to be related to a state of relaxation and dearousal. What is of relevance for the present report is that a behavior directed to the outer surface of the body is accompanied by a reduced attention towards the environment and is accompanied by a shift in the stream of information reaching the biological system, a shift from the information coming from the environment (exteroceptive information) to the information coming from within the organism (proprioceptive information) (Spruijt et al., 1992). This is the typical condition described as an internally oriented behavior (Aston-Jones et al., 1994).

\subsubsection{Diving}

The most powerful vagal reflex effects on the heart are elicited by diving. At the beginning of a dive, the heart rate of diving mammals such as seals, ducks and penguins (Ponganis and Kooyman, 2000) and of diving birds may reach very low values, around $5-10 \mathrm{bpm}$. This bradycardia is accompanied by peripheral vasoconstriction due to increases in sympathetic nerve activity. This pattern has been termed the "heart and brain" response (Folkow, 2000) and it is elicited by the stimulation of trigeminal afferents and of the ethmoidal nerve (Panneton et al., 2000).

From a behavioral point of view, diving is a protective behavior directed to escape from terrestrial predators and to seek for food. As a protective behavior, it is directed to save energy, mainly $\mathrm{O}_{2}$ consumption and temperature. In the context of the seawater environment, stress should be avoided to minimize muscle activity and oxygen consumption.

This reflex has been very well preserved amongst different diving species and a discussion of the implications for the amount of gene sequences necessary to the 
phylogenetic transmission and conservation has been presented (Hochachka, 2000).

The diving reflex may be elicited in man by cold water and cold wind stimulation of the face, and the response obtained is qualitatively similar to that obtained in diving mammals. In addition, in some individuals, the reflex effect may produce bradycardia down to $6 \mathrm{bpm}$, which indicates a highly conserved pattern of phylogenetic transmission among different species (Hochachka, 2000).

\subsubsection{Voluntary control of breathing}

It is well known that hypoxia activates the sympathetic activity, while slow and deep breathing, i.e. the voluntary control of breathing, is accompanied by an increase in vagal tone to the heart and circulation, as documented by decrements in heart rate and blood pressure, increase in the high frequency component and decrease in low frequency-high frequency ratio of power spectral analysis of heart rate variability and decrease in muscle sympathetic nerve activity (Pagani et al., 1986; Badra et al., 2001 Bernardi et al., 2001). These vagal effects are even more marked in yoga trainees, in whom a wakeful hypometabolic state has been demonstrated and related to the practice of transcendental meditation (Allison, 1970; Wallace et al., 1971; Stanescu et al., 1981; Bernardi et al., 2001). The increased vagal tone and hypometabolism have been explained in terms of mental relaxation (Bernardi et al., 2001), disengagement from the external environment (Allison, 1970) and heightened central control elicited by stimulation of pulmonary proprioceptive afferents and somatic sensory afferents (Stanescu et al., 1981).

\subsubsection{Post-exercise and post-stress recovery}

While the increase in heart rate during muscle exercise is considered to result from a combined parasympathetic withdrawal and sympathetic activation (Rowell, 1993), the fall in heart rate immediately after exercise, defined as the decrease in heart rate from peak exercise to $1 \mathrm{~min}$ after cessation of exercise (Cole et al., 1999), has been demonstrated to be primarily a function of the reactivation of parasympathetic activity, the sympathetic withdrawal playing a minor role (Cole et al., 1999). This vagal rebound effect, which in normal subjects is enhanced by physical training (Sugawara et al., 2001) while in heart failure patients is blunted (Imai et al., 1994; Pierpont et al., 2000), has been used as a prognostic marker and a predictor of mortality after myocardial infarction (La Rovere et al., 1995; Cole et al., 1999). It is of interest to note that this vagal rebound also occurs in mental arousal, after the termination of a psychological stress (Mezzacappa et al., 2001). All these data seem to support the notion that the heart rate decrease at the termination of a physical and psychological stress characterizes a vagal recovery and results from an active compensatory mechanism (Mezzacappa et al., 2001) based on a pre-determined, genetic, organization of function (Sugawara et al., 2001).

\subsubsection{Repetition of stimuli}

Physical conditioning is associated with typical adjustments of autonomic control of cardiovascular function such as resting bradycardia and lower exercise heart rate, reduced resting blood pressure and reduced sympathetic responses (plasma cathecolamines and muscle sympathetic nerve activity) at any given workload (O'Sullivan and Bell, 2000, 2001).

Trained subjects exhibit reduced tachycardia and pressor responses to handgrip exercise, the cold pressor and mental arithmetic tests (O'Sullivan and Bell, 2001).

Repetition of the stimulus seems to entrain a centrally mediated moderation of the emotional response that may be relevant in the adaptation of autonomic responses to training. It has been demonstrated that repetition of stimuli is by itself accompanied by a reduction in stress-related sympathetic responses because of a decrease in novelty of task and of the environment (Kelsey et al., 1999, 2000).

On the other hand, repetition of the same stimulus, facilitating a better central control, seems to play in favor of parasympathetic reinforcement, as demonstrated by the more pronounced bradycardia during deep breathing in yoga trainees (Bernardi et al., 2001).

It is not yet known, however, if an increased central voluntary control of skeletal muscle and an enhanced proprioceptive information from muscle afferents may contribute to this increased parasympathetic drive. Interestingly, secretion of a still unidentified pituitary growth factor has recently been shown to be induced by proprioceptive input from muscle afferents (McCall et al., 2001).

\subsection{Matter}

Matter exchanges are not considered in the present context, although with the exception of feeding as a purpose for diving, matter exchanges are usually absent during sleep and hibernation. During sleep, the small bowel is mostly quiescent and the colon appears to be virtually inert (Wingate, 1999).

\subsection{Energy}

From the above data, it appears that vagal activation, by decreasing the level of internal energy and the level of $\mathrm{O}_{2}$ consumption, is a necessary condition for the appearance of the hypometabolic states of hibernation, sleep and low level of metabolic energy intake. It is yet unknown, however, if the parasympathetic or a different neurohumoral, metabolic, endocrine factor or the genome itself are responsible for actively maintaining these states (Szekely, 2000; Milsom et al., 2001).

Worthy of interest is the recent demonstration that during hibernation in mammals, a metabolic shift away from the oxidation of carbohydrates and towards the combustion of stored fatty acids occurs (Buck et al., 2002), and that efferent vagal stimulation, in addition to depressing cardiac 
output, may induce a metabolic down-regulation (hypometabolism), primarily through an alteration of the systemic oxygen transport to metabolically active tissues (Platzack and Hicks, 2001). Recent data indicate, moreover, that neuronal nitric oxide and natriuretic peptides facilitate vagal control of heart rate (Chowdhary et al., 2001; Herring et al., 2001; Choate et al., 2001).

\subsection{Information}

Disengagement from the environment characterizes all the behaviors reported above which is accompanied by an increased vagal tone to the heart. Because the autonomic nervous system works as an interface amongst three different environments (Jänig and Häbler, 1999; Recordati, 2002), disengagement from the exteroceptive stimulation of the environment will favor the control by higher brain centers over the autonomic and to the so-called internally oriented behaviors (Aston-Jones et al., 1984). In addition, all the reported behaviors share the common aspect of being reactivation of the infant-mother relationship. If this relation is taken as an index of genetically transmitted information, it seems that during vagal predominance, the system mainly works on pre-determined information and on instinctually based patterns of response. The diving reflex, the gene sequence of which has been mapped, is a clear example in this sense (Hochachka, 2000).

\subsection{Summary}

All the reported behaviors share the common properties of disengagement from the external environment, recovery and restitution of function. The activation of the parasympathetic nervous system is thus directed to decrease energy mobilization and consumption and to prepare the visceral apparatus for an action to be performed by the BS on itself. Hence, the behavioral conditions characterized by a prevalence of parasympathetic tone share the following common properties: (1) low level of energy mobilization and utilization, (2) prevalence of proprioceptive information which is reinforced by repetition of stimuli and (3) at the extreme, absence of matter exchanges with the external environment (Table 1).

All these points are so intimately connected that each one seems to be a necessary condition for the appearance of the other. Self-protection and control necessarily imply a disengagement from the external environment and a low level of sympathetic activation. Just to quote a well-known example, the sleep hygiene rules advise how to best optimize sleep by avoiding large meals, vigorous exercise, hot showers and stressful work-related activities just before bedtime, keeping warm and comfortable during sleep and getting up at the same time each day (Ancoli-Israel, 2001; Czeisler et al., 2001). These instructions are directed to control and lower energy mobilization to adequately prepare the subject for the subsequent sleep period and to reinforce the onto- and phylogenetically based pattern of sleep (Ancoli-Israel, 2001).

\section{Discussion}

The biological system is an open thermodynamic system which exchanges matter, energy and information with the external environment. At least two main modalities of dealing with matter, energy and information exchanges are supported by the autonomic nervous system. One characterized by mobilization and utilization of metabolic energies, mainly driven by exteroceptive stimuli, is directed to perform an action in the external environment and is supported by the sympathetic. The other for self-protection and recovery, is mainly based on proprioceptive information, is directed to prepare the visceral apparatus for an action to be performed by the biological system on itself and it is supported by the parasympathetic. Worthy of notice is that while novelty of task and of the environment are the main drive for sympathetic activation, parasympathetic-driven behaviors are usually a repetition of the infant-mother relation and of evolutionarily acquired and genetically encoded patterns following well-known schemes for each group of mammals. These two main modalities of functional organization have been evinced by contrasting opposite behaviors characterized by a clear dominance of sympathetic or parasympathetic, such as strenuous muscle exercise and sleep. Both branches of the autonomic nervous system are always simultaneously active, however. Hence, in between the extreme behaviors, mixed patterns of sympathetic and parasympathetic activation and consequently of visceral functional expression are expected to occur.

These data confirm the ergotropic and trophotropicendophylactic theory of Hess (1957), the externally related activation of locus coeruleus neurons (Aston-Jones et al., 1984, 1994) as well as the relevance of parasympathetic innervation in behavioral development as proposed by the "polyvagal theory" (Porges, 1995, 2001). They also support the recently proposed thermodynamic theory of reference and the hypothesis that sympathetic and parasympathetic nervous systems may have originated, as branching solutions, from a common neuronal precursor (Prigogine, 1978; Recordati, 2002).

The sympathetic and parasympathetic activities are thus forces which may be considered to originate from hypothalamic centers with a given specific direction of action. To further underline this aspect, since a force with an application point, a direction and intensity may be physically and mathematically described by vectors, also sympathetic and parasympathetic activities may be described as directed vectorial forces. In addition to trophic neuronal, tissue and target organ factors well illustrated by the "social control" theory and by the "dual constraints" hypothesis about synapse formation (Bennett et al., 
2002), this notation might help to understand the driving neuronal force which contributes to the reinnervation of previously denervated or transplanted visceral organs.

When evaluated at the target organ level, these forces are usually described as antagonistic and opposite, although, as in the case of pupils, they are directed to different target structures (Jänig and Häbler, 1999). When seen in the context of the circadian behavioral alternance, on the other hand, it clearly appears that each modality of action is a necessary condition for the appearance of the other. As demonstrated by the sleep deprivation studies, for example, alertness cannot be endlessly maintained without being properly interspaced by regular recovery periods (AncoliIsrael, 2001). From a behavioral point of view, sympathetic and parasympathetic dominance, therefore, is better described as reciprocal rather than antagonistic (Jänig and Häbler, 1999). It is the functional expression of the inherited circadian rhythmicity and of eons of time of adaptation to the environment.

On this basis and along the thermodynamic hypothesis, an attempt to a synthetic description of the autonomic nervous system functional organization as an outcome of its evolutionary history may be:

The autonomic nervous system is a nervous structure which utilizes (i.e. dissipates) energy to do a biological work (hence a "dissipative structure"). This work results from the application of forces whose type, intensity, direction and distribution are also dependent from the prevalent behavior (directed forces are usually defined "vectors"). Owing to the plastic neuronal properties of the autonomic nervous system, inputs from forebrain areas, fluid matrix and external environment may contribute to shaping the functional organization of the system and to modifying its output to visceral organs. The inherent and entrained rhythmicity of the autonomic nervous system, together with the wide range of visceral functional expression it may induce, allow to view the functional organization of the system as the result of a continuous interplay between structure, function and fluctuations ("fluctuations": changes around an average value of some physical quantity in time).

\subsection{Cannon, Hess and Pick}

The present proposal contrasts with the homeostatic theory of Cannon (1929) which describes the constancy of the internal variable as the main objective of the autonomic nervous system in general and of the sympathetic in particular. As seen in the present review, the sympathetic nervous system promotes changes in the visceral apparatus, increases gradients, mobilizes energies and markedly alters many, if not all, measurable variables of the internal environment (Recordati, 1984, 2002). This is in full accordance with the dynamogenic hypothalamic theory by Hess (1957, p. 35). The parasympathetic, on the other hand, as clearly recog- nized by Cannon (1953) in his last book, is the autonomic nervous system division which promotes restitution and recovery. As already suggested (Recordati, 1984, 1989; Porges, 1995), it is the parasympathetic, not the sympathetic, which is the true homeostatic agent, the sympathetic action being better described by its "emergency" function. Both homeostasis and emergency theories should therefore be reassigned to the description of parasympathetic and sympathetic function, respectively (Cannon, 1929, 1953; Cannon et al., 1929; Recordati, 1984, 1989, 2002; Porges, 1995, 2001). Along this proposal, Hess's, Pick's and Cannon's hypotheses would be in agreement with one another: the sympathetic is the ergotropic system (Hess, 1957; Porges, 1995, 2001), mainly active in emergency conditions (Cannon, 1953) with a catabolic function (Pick, 1970); while the trophotropic-endophylactic parasympathetic system (Hess, 1957) becomes the homeostatic agency (Cannon, 1929) favoring an anabolic function and hypometabolism (Table 2) (Pick, 1970; Recordati, 1984, 1989, 2002).

\subsection{Perspectives}

The above conclusions about the functional organization of the two main divisions of the autonomic nervous system, together with the available clinical data, indicate that an enhanced and sustained increase in sympathetic tone when accompanied by a simultaneous decrease in vagal activity may constitute an additional and important risk factor for cardiovascular diseases and may contribute to worsen prognosis of already established cardiovascular pathophysiological conditions (Zanchetti, 1986; Frattola et al., 1993; Julius, 1996; Folkow, 2000; Esler et al., 2001; Malliani and Montano, 2002; Curtis and O'Keefe, 2002).

Both biological and clinical data indicate, for example, primary arterial hypertension as a sympathetic nervous system-dependent disorder. Generally disappointing have been until now the results of studies addressed to demonstrate a prominent genetic basis for this diseased state (Smithies et al., 2000). This condition has also been interpreted as a "civilization disorder", reflecting an excessive response to stimuli, the so-called "hot responder trait",

Table 2

Theories about the functional role of the two main divisions of the autonomic nervous system

\begin{tabular}{|l|ll|}
\hline & Sympathetic & Parasympathetic \\
\hline WB Cannon & $\begin{array}{l}\text { Homeostasis } \\
\text { Emergency }\end{array}$ & Homeostasis \\
\hline WR Hess & Ergotropic & Trophotropic \\
\hline J Pick & Catabolic & Anabolic \\
\hline $\begin{array}{l}\text { Thermodynamic } \\
\text { hypothesis }\end{array}$ & $\begin{array}{l}\text { Work related to the } \\
\text { external environment }\end{array}$ & $\begin{array}{l}\text { Work related to the } \\
\text { internal environment, } \\
\text { self-protection and recovery }\end{array}$ \\
\hline
\end{tabular}

The present proposal readdresses ( $\longrightarrow$ ) the homeostatic theory to the description of the functional role of the parasympathetic rather than of the sympathetic system as originally proposed by WB Cannon. 
and an imbalance between the two main divisions of the autonomic nervous system (Folkow, 2000; Light, 2001; Curtis and O'Keefe, 2002). Stressful conditions, when prolonged and sustained, accompanied by enhanced exteroceptive stimulation, may give rise in susceptible individuals to a specific stress-dependent differential organization of the sympathetic not adequately balanced by a simultaneous increase in parasympathetic recovery function (Esler et al., 2001; Morrison, 2001). Environmental stimuli favoring a sensitization process of postganglionic sympathetic neurons (Jänig et al., 1982; Blumberg and Jänig, 1983) similar to that described for the gill withdrawal reflex of aplysia and hippocampal networks (Kandel, 2001) may reinforce the sympathetic tone, induce a neurogenic hyperkinetic state (Julius, 1996; Julius and Majahalme, 2000) and increase blood pressure variability (Frattola et al., 1993). Positive sympathetic reflexes (Malliani and Montano, 2002) sympathetic-renin-angiotensin interactions (Recordati et al., 2000), faulty noradrenaline reuptake into the cardiac sympathetic nerves (Rumantir et al., 2000; Esler et al., 2001) and sympathetic cotransmitter control of blood vessels (Burnstock, 2002) may also come into play. The beneficial effects in hypertensive patients of aerobic muscle exercise, low metabolic energy intake, low $\mathrm{Na}+$ diet, decreased stress level and mental relaxation, which all positively contribute to increase parasympathetic cardiac and circulatory control and lower sympathetic activity and arterial blood pressure, may favor the point of view that primary hypertension may be caused by a pathophysiological imbalance of the autonomic nervous system regulatory function.

In conclusion, a thermodynamic approach to the biological system may help to formulate a coherent hypothesis about the autonomic nervous system development and about the reciprocal functional specificity acquired by the sympathetic and parasympathetic divisions in the course of evolution. On this background, a logical continuity is reestablished among the work of our predecessors and between theories, experimental and clinical observations.

\section{Acknowledgements}

The critical reviews and the constructive comments by Prof. A. Zanchetti, University of Milan, and by Prof. E.R. Perl, University of North Carolina at Chapel Hill, are gratefully acknowledged.

\section{References}

Allison, J., 1970. Respiratory changes during transcendental meditation. Lancet $651,833-834$.

Ancoli-Israel, S., 2001. "Sleep is not tangible" or what the Hebrew tradition has to say about sleep. Psychosom. Med. 73, 778-787.

Aronne, L.J., Mackintosh, R., Rosenbaum, M., Leibel, R.L., Hirsch, J., 1995. Autonomic nervous system activity in weight gain and weight loss. Am. J. Physiol. 269, R222-R225.
Aston-Jones, G., Foote, S.L., Bloom, F.E., 1984. Anatomy and physiology of locus coeruleus neurons: functional implications. In: Ziegler, N., Lake, C.R. (Eds.), Norepinephrine (Frontiers of Clinical Neuroscience). Williams \& Wilkins, Baltimore, MD, pp. 92-116.

Aston-Jones, G., Valentino, R.J., Van Bockstaele, E.J., Meyerson, A.T., 1994. Locus coeruleus, stress, and PTSD: neurobiological and clinical parallels. In: Murburg, M. (Ed.), Cathecolamine Function in Post Traumatic Stress Disorders: Emerging Concepts. American Psychiatric Press, Washington, DC, pp. 17-62.

Badra, L.J., Cooke, W.H., Hoag, J.B., Crossman, A.A., Kuusela, T.A., Tahvanainen, K.U.O., Eckberg, D.L., 2001. Respiratory modulation of human autonomic rhythms. Am. J. Physiol. 280, H2674-H2688.

Bell, C., Seals, D.R., Monroe, M.B., Day, D.S., Shapiro, L.F., Johnson, D.G., Jones, P.P., 2001. Tonic sympathetic support of metabolic rate is attenuated with age, sedentary lifestyle, and female sex in healthy adults. J. Clin. Endocrinol. Metab. 86, 4440-4444.

Benarroch, E.E., 1999. Functional anatomy of the central autonomic nervous system. In: Appenzeller, O. (Ed.), Handbook of Clinical Neurology. The Autonomic Nervous System: Part I. Normal Functions, vol. 74. Elsevier, Amsterdam, pp. 53-86.

Bennett, M.R., Gibson, W.G., Lemon, G., 2002. Neuronal cell death, nerve growth factor and neurothrophic models: 50 years on. Auton. Neurosci. 95, $1-23$.

Bernardi, L., Passino, C., Wilmerding, V., Dallam, G.M., Parker, D.L., Robergs, R.A., Appenzeller, O., 2001. Breathing patterns and cardiovascular autonomic modulation during hypoxia induced by simulated altitude. J. Hypertens. 19, 947-958.

Blumberg, H., Jänig, W., 1983. Enhancement of resting activity in postganglionic vasoconstrictor neurons following short-lasting repetitive activation of preganglionic axons. Pflügers Arch. 396, 89-94.

Buck, M.J., Squire, T.L., Andrews, M.T., 2002. Coordinate expression of the PDK4 gene: a means of regulating fuel selection in a hibernating mammal. Physiol. Genomics 8, 5-13.

Burke, S.L., Malpas, S.C., Head, G.A., 1998. Effect of rilmenidine on the cardiovascular responses to stress in the conscious rabbit. J. Auton. Nerv. Syst. 72, 177-186.

Burnstock, G., 2002. Potential therapeutic targets in the rapidly expanding field of purinergic signaling. Clin. Med. 2, 45-53.

Cannon, W.B., 1929. Organization for physiological homeostasis. Physiol. Rev. 9, 399-431.

Cannon, W.B., 1953. Bodily changes in pain, hunger, fear and rage. Branford, Boston, CT

Cannon, W.B., Newton, H.T., Bright, E.M., Menkin, V., Moore, R.M., 1929. Some aspects of the physiology of animals surviving complete exclusion of the sympathetic nerve impulses. Am. J. Physiol. 89, 84-107.

Choate, J.K., Danson, E.J., Morris, J.F., Paterson, D.J., 2001. Peripheral vagal control of heart rate is impaired in neuronal NOS knockout mice. Am. J. Physiol. 281, H2310-H2317.

Chowdhary, S., Nuttall, S.L., Coote, J.H., Townend, J.N., 2001. L-arginine augments cardiac vagal control in healthy human subjects. Hypertension 39, 51-56.

Clarkson, P.M., Thompson, H.S., 1997. Drugs and sport. Research findings and limitations. Sports Med. 24, 366-384

Cole, C.R., Balckstone, E.H., Pashkow, F.J., Snader, C.E., Lauer, M.S., 1999. Heart-rate recovery immediately after exercise as a predictor of mortality. N. Engl. J. Med. 341, 1351-1357.

Conway, J., Boon, N., Jones, J.V., Sleight, P., 1983. Involvement of the baroreceptor reflexes in the changes in blood pressure with sleep and mental arousal. Hypertension 5, 746-748.

Conway, J., Boon, N., Davies, C., Vann Jones, J., Sleight, P., 1984. Neural and humoral mechanisms in blood pressure variability. J. Hypertens. 2, 203-208.

Coote, J.H., Bothams, V.F., 2001. Cardiac vagal control before, during and after exercise. Exp. Physiol. 86, 811-815.

Coote, J.H., Hilton, S.M., Perez-Gonzalez, J.F., 1971. The reflex nature of the pressor response to muscular exercise. J. Physiol. 215, 789-804.

Curtis, B.M., O'Keefe, J.H., 2002. Autonomic tone as a cardiovascular 
risk factor: the dangers of chronic fight and flight. Mayo Clin. Proc. $77,45-54$.

Czeisler, C.A., Winkelman, J.W., Richardson, G.S., 2001. Sleep disorders. In: Braunwald, E., Fauci, A.S., Kasper, D.L., Hauser, S.L., Longo, D.L., Jameson, J.L. (Eds.), Principles of Internal Medicine, 15th ed. McGrawHill, New York, pp. 155-163.

Dampney, R.A.L., 1994. Functional organization of central pathways regulating the cardiovascular system. Physiol. Rev. 74, 323-364.

DiCarlo, S.E., Bishop, V.S., 1999. Exercise and the autonomic nervous system. In: Appenzeller, O. (Ed.), Handbook of Clinical Neurology. The Autonomic Nervous System: Part I. Normal Functions, vol. 74. Elsevier, Amsterdam, pp. 245-272.

Elam, M., Svensson, T.H., Thoren, P., 1986. Locus coeruleus neurons and sympathetic nerves activation by cutaneous sensory afferents. Brain Res. 366, 254-261.

Esler, M.D., Rumantir, M., Kaye, D., Lambert, G., 2001. The sympathetic neurobiology of essential hypertension: disparate influences of obesity, stress, and noradrenaline transporter dysfunction? Am. J. Hypertens. 14, 139S-146S.

Folkow, B., 2000. Perspectives on the integrative functions of the 'sympatho-adrenomedullary system'. Auton. Neurosci. 83, 101-115.

Frattola, A., Parati, G., Cuspidi, C., Albini, F., Mancia, G., 1993. Prognostic value of 24-hour blood pressure variability. J. Hypertens. 11, $1133-1137$.

Furlan, R., Guzzetti, S., Crivellaro, W., Dassi, S., Tinelli, M., Baselli, S., Cerutti, S., Lombardi, F., Pagani, M., Malliani, A., 1990. Continuous 24-hour assessment of the neural regulation of systemic arterial pressure and RR variabilities in ambulant subjects. Circulation $81,537-547$.

Furness, J.B., Kunze, W.A.A., Clerc, N., 1999. Nutrient tasting and signalling mechanisms in the gut: Part II. The intestine as a sensory organ: neural, endocrine and immune responses. Am. J. Physiol. 277, G922-G928.

Henry, J.P., 1994. Psychological stress and hypertension. In: Swales, J.D. (Ed.), Textbook of Hypertension. Blackwell, London, pp. 633-639.

Henry, J.P., 1997. Psychological and physiological responses to stress: the right hemisphere and the hypothalamo-pituitary-adrenal axis, an inquiry into problems of human bonding. Acta Physiol. Scand., Suppl. $640,10-25$.

Herring, N., Zaman, J.A., Paterson, D.J., 2001. Natriuretic peptides like NO facilitate cardiac vagal neurotransmission and bradycardia via a cGMP pathway. Am. J. Physiol. 281, H2318-H2327.

Hess, W.R., 1957. The Functional Organization of the Diencephalon. Grune \& Stratton, New York.

Hirsch, J., Leibel, R.L., Mackintosh, R., Aguirre, A., 1991. Heart rate variability as a measure of autonomic function during weight change in humans. Am. J. Physiol. 261, R1418-R1423.

Hobson, J.A., Steriade, M., 1986. Neuronal basis of behavioral state control. In: Mountcastle, V.B., Bloom, F.E., Geiger, S.R. (Eds.), Handbook of physiology. Sect. 1. The Nervous System: Vol. IV. Intrinsic Regulatory Systems of the Brain. Am. Physiol. Soc., Bethesda, MD, pp. 796-800.

Hochachka, P.W., 2000. Pinned diving response mechanism and evolution: a window on the paradigm of comparative biochemistry and physiology. Comp. Biochem. Physiol. 126, 435-458.

Hoffman, B.B., 2001. Catecholamines, sympathomimetic drugs, and adrenergic receptor antagonism. In: Hardman, J.G., Limbird, L.E. (Eds.), The Pharmacological Basis of Therapeutics, 10th ed. McGraw-Hill, New York, pp. 215-268. Chap. 10.

Iellamo, F., Pizzinelli, P., Massaro, M., Raimondi, G., Peruzzi, G., Lagramante, J.M., 1999. Muscle metoboreflex contribution to sinus node regulation during static exercise: insights from spectral analysis of heart rate variability. Circulation 100, 27-32.

Imai, K., Sato, H., Hori, M., et al., 1994. Vagally mediated heart rate recovery after exercise is accelerated in athletes but blunted in patients with chronic heart failure. J. Am. Coll. Cardiol. 24, 1529-1535.

Iwase, S., Mano, T., Cui, J., Kitazawa, H., Kamiya, A., Miyazaki, S.,
Sugiyama, Y., Mukai, C., Kohno, M., Nagaoka, S., 1998. Changes in muscle sympathetic nerve activity and effect of breathing maneuvers during microgravity induced by parabolic flight in humans. Environ. Med. 42, 152-155.

Jänig, W., 1988. The function of the autonomic system as interface between body and environment. Old and new concepts: W.B. Cannon and W.R. Hess revisited. In: Hellhammer, D., Florin, I., Weiner, H. (Eds.), Neurobiological Approaches to Human Disease. Hans Huber Publisher, Bern, pp. $143-173$.

Jänig, W., Häbler, H.-J., 1999. Organization of the autonomic nervous system: structure and function. In: Appenzeller, O. (Ed.), Handbook of Clinical Neurology. The Autonomic Nervous System: Part I. Normal Functions, vol. 74. Elsevier, Amsterdam, pp. 1-52.

Jänig, W., McLachlan, E.M., 1999. Neurobiology of the autonomic nervous system. In: Mathias, C.J., Bannister, R. (Eds.), Autonomic Failure. Oxford Univ. Press, Oxford, pp. 3-15.

Jänig, W., Krauspe, R., Wiedersatz, G., 1982. Transmission of impulses from pre- to postganglionic vasoconstrictor and sudomotor neurons. J. Auton. Nerv. Syst. 6, 95-106.

Julius, S., 1996. The evidence for a pathophysiologic significance of the sympathetic overactivity in hypertension. Clin. Exp. Hypertens. 18, $305-321$.

Julius, S., Majahalme, S., 2000. The changing face of sympathetic overactivity in hypertension. Ann. Med. 32, 365-370.

Kandel, E.R., 2001. The molecular biology of memory storage: a dialogue between genes and synapses. Science 294, 1030-1038.

Kelsey, R.M., Blascovich, J., Tomaka, J., Leitten, C.L., Schneider, T.R., Wiens, S., 1999. Cardiovascular reactivity and adaptation to recurrent psychological stress: effects of prior task exposure. Psychophysiology 36, 818-831.

Kelsey, R.M., Blascovich, J., Leitten, C.L., Schneider, T.R., Tomaka, J., Wiens, S., 2000. Cardiovascular reactivity and adaptation to recurrent psychological stress: the moderating effects of evaluative observation. Psychophysiology 37, 748-756.

Kilduff, T.S., Krilowicz, B., Milsom, W.K., Trachsel, L., Wang, L.C., 1993. Sleep and mammalian hibernation: homologous adaptations and homologous processes? Sleep 16, 372-386.

Landsberg, L., Young, J.B., 1978. Fasting, feeding and regulation of the sympathetic nervous system. N. Engl. J. Med. 298, 1295-1301.

Landsberg, L., Saville, M.E., Young, J.B., 1984. Sympathoadrenal system and regulation of thermogenesis. Am. J. Physiol. 247, E181-E189.

La Rovere, M.T., Bigger, J.T., Marcus, F.I., Mortara, A., Schwartz, P.J., 1995. Baroreflex sensitivity and heart-rate variability in prediction of total cardiac mortality after myocardial infarction. Lancet $35,830-836$.

Le Doux, J.E., 1987. Emotions. In: Mountcastle, V.B., Plum, F., Geiger, S.R. (Eds.), Handbook of Physiology, Sect. 1, The Nervous System: Vol. V. Higher Functions of the Brain, Part 1. Am. Physiol. Soc., Bethesda, MD, pp. $419-459$.

Light, K.C., 2001. Hypertension and the reactivity hypothesis: the next generation. Psychosom. Med. 63, 744-746.

Lugaresi, E., Provini, F., Cortelli, P., 2001. Sleep embodies maximum and minimum levels of autonomic integration. Clinic. Auton. Res. 11, 5-10.

Macefield, V.G., Elam, M., Wallin, B.G., 2002. Firing properties of single postganglionic sympathetic neurons recorded in awake human subjects. Auton. Neurosci. 95, 146-159.

Malliani, A., 2000. Principles of Cardiovascular Neural Regulation in Health and Disease. Kluwer Academic Publishing, Boston.

Malliani, A., Montano, N., 2002. Emerging excitatory role of cardiovascular sympathetic afferents in pathophysiological conditions. Hypertension $39,63-68$.

Mancia, G., Baccelli, G., Zanchetti, A., 1974. Regulation of renal circulation during behavioral changes in the cat. Am. J. Physiol. 227, $536-542$.

Mark, A.L., Victor, R.G., Nerhed, C., Wallin, B.G., 1985. Microneurographic studies of the mechanism of sympathetic nerve responses to static exercise in humans. Circ. Res. 57, 461-469.

Mazursky, J.E., Segar, J.L., Nuyt, A.-M., Smith, B.A., Robillard, J.E., 
1996. Regulation of renal sympathetic nerve activity at birth. Am. J. Physiol. 270, R86-R93.

McAllen, R.M., Malpas, S.C., 1997. Sympathetic burst activity: characteristics and significance. Clin. Exp. Pharmacol. Physiol. 24, 791-799.

McCall, G.E., Gosselink, K.L., Bigbe, A.J., Roy, R.R., Grindeland, R.E., Edgerton, V.R., 2001. Muscle afferent-pituitary axis: a novel pathway for modulating the secretion of a pituitary growth factor. Exerc. Sport Sci. Rev. 29, 164-169.

Mcdonald, I.A., 1999. The influence of the autonomic nervous system on metabolic function. In: Mathias, C.J., Bannister, R. (Eds.), Autonomic Failure. Oxford Univ. Press, Oxford, pp. 136-142.

Mezzacappa, E.S., Kelsey, R.M., Katkin, E.S., Sloan, R.P., 2001. Vagal rebound and recovery from psychological stress. Psychosom. Med. 63, $650-657$.

Milsom, W.K., Zimmer, M.B., Harris, M.B., 2001. Vagal control of cardiorespiratory function in hibernation. Exp. Physiol. 86, 791-796.

Monroe, M.B., Seals, D.R., Shapiro, L.F., Bell, C., Johnson, D., Jones, P.P., 2001. Direct evidence for tonic sympathetic support of resting metabolic rate in healthy adult humans. Am. J. Physiol. 280, E740-E744.

Morrison, S.F., 2001. Differential control of sympathetic outflow. Am. J. Physiol. 281, R683-R698.

Moruzzi, G., 1969. Sleep and instinctive behavior. Arch. Ital. Biol. 107, $175-216$.

Moruzzi, G., 1979. Fisiologia della vita di relazione. Utet II ed, Torino. pp. 180 .

Nagashima, K., Nakai, S., Tanaka, M., Kanosue, K., 2000. Neuronal circuitries involved in thermoregulation. Auton. Neurosci. 85, 18-25.

Nicolis, G., Prigogine, I., 1977. Self-Organization in Non-Equilibrium Systems. Wiley, New York.

Omodeo, P., 1983. The theory of living being and evolution. Scientia 118, $51-64$.

Opie, L.H., 1985. Effect of beta-adrenergic blockade on biochemical and metabolic response to exercise. Am. J. Cardiol. 55, 95D-100D.

O'Sullivan, S.E., Bell, C., 2000. The effects of exercise and training on human cardiovascular reflex control. J. Auton. Nerv. Syst. 81, 16-24.

O'Sullivan, S.E., Bell, C., 2001. Training reduces autonomic cardiovascular responses to both exercise-dependent and -independent stimuli in humans. Auton. Neurosci. 91, 76-84.

Overton, J.M., Williams, T.D., Chambers, J.B., Rashotte, M.E., 2001. Central leptin infusion attenuates the cardiovascular and metabolic effects of fasting in rats. Hypertension 37, 663-669.

Pagani, M., Lombardi, F., Guzzetti, S., Rimoldi, O., Furlan, R., Pizzinelli, P., Sandrone, G., Malfatto, G., Dell'Orto, S., Piccaluga, E., Turiel, M., Baselli, G., Cerutti, S., Malliani, A., 1986. Power spectral analysis of heart rate and arterial pressure variabilities as a marker of sympathovagal interaction in man and conscious dog. Circ. Res. 59, 178-193.

Pagani, M., Somers, V.K., Furlan, R., Dell'Orto, S., Conway, J., Baselli, G., Cerutti, S., Sleight, P., Malliani, A., 1988. Changes in autonomic regulation induced by physical training in mild hypertension. Hypertension $12,600-610$.

Panneton, W.M., McCulloch, P.F., Sun, W., 2000. Trigemino-autonomic connections in the muskrat: the neural substrate for the diving response. Brain Res. 874, 48-65.

Parmeggiani, P.L., 1985. Homeostatic regulation during sleep: facts and hypothesis. In: McGinty, D.J., et al. (Ed.), Brain Mechanisms of Sleep. Raven Press, New York, pp. 385-397.

Petretta, M., Bonaduce, D., Scalfi, L., de Filippo, E., Marciano, F., Migaux, M.L., Themistoclakis, S., Ianniciello, A., Contaldo, F., 1997. Heart rate variability as a measure of autonomic nervous system function in anorexia nervosa. Clin. Cardiol. 20, 219-224.

Piazza, S., Furlan, R., Dell'Orto, S., Porta, A., Lombardi, F., Pagani, M., Malliani, A., 1995. Mechanical effects of respiration and stepping on systolic arterial pressure variability during treadmill exercise. J. Hypertens. $13,1643-1647$.

Pick, J., 1970. The Autonomic Nervous System. JB Lippincott, Philadelphia. pp. 359-363.

Pierpont, G.L., Stolpman, D.R., Gornick, C.C., 2000. Heart rate recovery post-exercise as an index of parasympathetic activity. J. Auton. Nerv. Syst. $80,169-174$.

Platzack, B., Hicks, J.W., 2001. Reductions in systemic oxygen delivery induce hypometabolic state in the turtle Trachemys scripta. Am. J. Physiol. 281, R1295-R1301.

Ponganis, P.J., Kooyman, G.L., 2000. Diving physiology of birds: a history of studies on polar species. Comp. Biochem. Physiol. 126, 143-151.

Porges, S.W., 1995. Cardiac vagal tone: a physiological index of stress. Neurosci. Biobehav. Rev. 19, 225-233.

Porges, S.W., 2001. The polyvagal theory: phylogenetic substrates of a social nervous system. Int. J. Psychophysiol. 42, 123-146.

Prigogine, I., 1973. Irreversibility as a symmetry-breaking process. Nature 246, 67-71.

Prigogine, I., 1975. Physique et metaphysique. In: Connaissance, scientifique et philosophie, Pubblication de Deuxième Centenaire, Académie Royale de Belgique, (Italian translation as Fisica e Metafisica In: La Nuova Alleanza. Ed I. Prigogine. Milano, Longanesi, 1979, pp. 155-183).

Prigogine, I., 1978. Time, structure and fluctuations. Science 201, 777-785.

Prigogine, I., 1996. The End of Certainty. The Free Press, New York, pp. $17-29$.

Reaven, G.M., Lithell, H., Landsberg, L., 1996. Hypertension and associated metabolic abnormalities - the role of insulin resistance and the sympathoadrenal system. N. Engl. J. Med. 334, 374-381.

Recordati, G., 1984. The functional role of the visceral nervous system. A critical evaluation of Cannon's "Homeostatic" and "Emergency" theories. Arch. Ital. Biol. 122, 249-267.

Recordati, G., 1989. The visceral nervous system: homeostasis and the dissipative structure. International Union of Physiological Sciences, Satellite Symposium on: Central and Peripheral Interrelations between Blood Pressure Control Mechanisms, Abstract Book, Rostock/GDR, pp. $20-21$.

Recordati, G., 2002. The visceral nervous system and its environments. J. Theor. Biol. 214, $293-304$.

Recordati, G., Zorzoli, F., Zanchetti, A., 2000. Effects of a reversible 'nephrectomy' on renal sympathetic activity and blood pressure in the rat: evidence for an acute angiotensin-mediated hypertension. J. Hypertens. $18,1277-1287$

Rissanen, P., Franssila-Kallunki, A., Rissanen, A., 2001. Cardiac parasympathetic activity is increased by weight loss in healthy obese women. Obes. Res. 9, 637-643.

Rowell, L.B., 1993. Human Cardiovascular Control. Oxford Univ. Press, Oxford.

Rumantir, M.S., Kaye, D.M., Jennings, G.L., Vaz, M., Hastings, J.A., Esler, M.D., 2000. Phenotypic evidence of faulty neuronal norepinephrine reuptake in essential hypertension. Hypertension 36, 824-829.

Sakaguchi, T., Arase, K., Fisler, J.S., Bray, G.A., 1988. Effect of starvation and food intake on sympathetic activity. Am. J. Physiol. 255, R284-R288.

Scholz, U.J., Bianchi, A.M, Cerutti, S., Kubicki, S., 1997. Vegetative background of sleep: spectral analysis of the heart rate variability. Physiol. Behav. 62, 1037-1043.

Schwartz, M.W., Seeley, R.J., 1997. Neuroendocrine responses to starvation and weight loss. N. Engl. J. Med. 336, 1802-1811.

Seals, D.R., 1993. Influence of active muscle size on sympathetic nerve discharge during isometric contractions in humans. J. Appl. Physiol. 75, $1426-1431$.

Segar, J.L., 1997. Ontogeny of the arterial and cardiopulmonary baroreflex during fetal and postnatal life. Am. J. Physiol. 273, R457-R471.

Segar, J.L., Mazursky, J.E., Robillard, J.E., 1994. Changes in ovine renal sympathetic nerve activity and baroreflex function at birth. Am. J. Physiol. 267, H1824-H1832.

Shepherd, J.T., 1985. Circulatory response to beta-adrenergic blockade at rest and during exercise. Am. J. Cardiol. 55, 87D-94D.

Smithies, O., Kim, H.-S., Takahashi, N., Edgell, M.H., 2000. Importance of quantitative genetic variations in the etiology of hypertension. Kidney Int. $58,2265-2280$. 
Smyth, H.S., Sleight, P., Pickering, G.W., 1969. Reflex regulation of arterial pressure during sleep in man: a quantitative method of assessing baroreflex sensitivity. Circ. Res. 24, 109-121.

Somers, V.K., Dyken, M.E., Mark, A.L., Abboud, F.M., 1993. Sympathetic-nerve activity during sleep in normal subjects. N. Engl. J. Med. 328, 303-307.

Spruijt, B.M., Van Hooff, J.A.R.A.M., Gispen, W.H., 1992. Ethology and neurobiology of grooming behavior. Physiol. Rev. 72, 825-852.

Spyer, K.M., 1999. Central nervous control of the cardiovascular system. In: Mathias, C.J., Bannister, R. (Eds.), Autonomic Failure. Oxford Univ. Press, Oxford, pp. 45-55.

Stanescu, D.C., Nemery, B., Veriter, C., Marechal, C., 1981. Pattern of breathing and ventilatory response to $\mathrm{CO}_{2}$ in subjects practicing hatha-yoga. J. Appl. Physiol. 51, 1625-1629.

Sugawara, J., Murakami, H., Maeda, S., Kuno, S., Matsuda, M., 2001. Change in post-exercise vagal reactivation with exercise training and detraining in young men. Eur. J. Appl. Physiol. 85, 259-263.

Szekely, M., 2000. The vagus nerve and energy metabolism. Auton. Neurosci. $85,26-38$.

Tyrer, P., 1988. Current status of beta-blocking drugs in the treatment of anxiety disorders. Drugs 36, 773-783.

Usher, M., Cohen, J.D., Servan-Schreiber, D., Rajkowski, J., Aston-Jones, G., 1999. The role of locus coeruleus in the regulation of cognitive performance. Science 283, 549-554.

Van Bockstaele, E.J., Aston-Jones, G., 1995. Integration in the ventral medulla and coordination of sympathetic, pain and arousal functions. Clin. Exp. Hypertens. 17, 153-165.

Victor, R.G., Pryor, S.L., Secher, N.H., Mithchell, J.H., 1989. Effects of partial neuromuscular blockade on sympathetic nerve responses to static exercise in humans. Circ. Res. 65, 468-476.

von Bertalannfy, L., 1950. The theory of open systems in physics and biology. Science 111, 23-29.

von Bertalannfy, L., 1969. General System Theory. George Braziller, New York. pp. $41-42$.

Wallace, R.K., Benson, H., Wilson, A.F., 1971. A wakeful hypometabolic physiologic state. Am. J. Physiol. 221, 795-799.

Wingate, D.L., 1999. Autonomic function and dysfunction in the gastrointestinal tract. In: Mathias, C.J., Bannister, R. (Eds.), Autonomic Failure. Oxford Univ. Press, Oxford, pp. 271-282.

Zanchetti, A., 1986. Volhard lecture: sympatho-renal interactions and blood pressure control. J. Hypertens. 4 (Suppl. 6), S4-S13.

Zanchetti, A., Baccelli, G., Mancia, G., Ellison, G.D., 1972. Emotion and the cardiovascular system in the cat. Physiology, Emotion and Psychosomatic Illness. Ciba Foundation Symposium 8 (new series), Elsevier, Amsterdam, pp. 201-223.

Zieglgänsberger, W., 1986. Central control of nociception. In: Mountcastle, V.B., Bloom, F.E., Geiger, S.R. (Eds.), Handbook of Physiology, Sect. 1, The Nervous System: Vol. IV. Intrinsic Regulatory Systems of the Brain. Am. Physiol. Soc., Bethesda, MD, pp. 581-645. 